\title{
Intuitionistic fuzzy model for reliability management in wind turbine system
}

\author{
Daniel O. Aikhuele \\ College of Engineering, Bells University of Technology, Ota, Nigeria
}

\begin{abstract}
A flexible model which is based on a Triangular intuitionistic flexibility ranking and aggregating (TIFRA) operator is proposed for failure detection and reliability management in a Wind Turbine system. The model which is employed when there are limited research data and valid source of information, uses expert-based knowledge/opinion for failure detection and reliability management. The results from the study concludes that, the most important area affected by failure with respect to the failure criteria used, includes; oil level sensor tilt sensors for tower installation and accelerometers for tower sway $\left(\mathrm{A}_{2}\right)$, Pressure sensor for blade monitoring $\left(\mathrm{A}_{3}\right)$, and the Pitch actuator $\left(\mathrm{A}_{4}\right)$. The main advantage of the proposed method is that it provides advanced information about faults that identifies the intensity of the system behavior also; the method provides a more complete view of the reliability management and root cause of failure in the Wind Turbine (WT) system using the flexibility parameter in the model.
\end{abstract}

Keywords Failure detention, Reliability management, Wind Turbine system, Expert opinion,

Triangular intuitionistic flexibility ranking and aggregating model

Paper type Original Article

\section{Introduction}

Wind Turbine technology which is an alternative source of power formation, is a sophisticated and complex system with high automation processes [1]. The increasing technological advancement of today's wind power source and its high rate of used in modern Towns and Cities have increased the concerns of its component maintenance repairing. Healthy reliability management study and failure detection which is a requirement for a reliable continuous operations and maintenance of machines systems [2,3] and for wind turbines on the remote access [4]. Can be described as one of the fundamentals in today's Modern industrial wind turbine (WT) systems and a pre-requisite to ensuring a sustainable failure prediction maintenance [5]. Furthermore, the idea of failure diagnosis in mechanical systems like WT is to detect the exact faults location, as well as to determine its extent in the systems [6].

\footnotetext{
(C) Daniel O. Aikhuele. Published in Applied Computing and Informatics. Published by Emerald Publishing Limited. This article is published under the Creative Commons Attribution (CC BY 4.0) license. Anyone may reproduce, distribute, translate and create derivative works of this article (for both commercial and non-commercial purposes), subject to full attribution to the original publication and authors. The full terms of this license may be seen at http://creativecommons.org/licences/by/4.0/legalcode

Publishers note: The publisher wishes to inform readers that the article "Intuitionistic fuzzy model for reliability management in wind turbine system" was originally published by the previous publisher of Applied Computing and Informatics and the pagination of this article has been subsequently changed. There has been no change to the content of the article. This change was necessary for the journal to transition from the previous publisher to the new one. The publisher sincerely apologises for any inconvenience caused. To access and cite this article, please use Aikhuele, D. O. (2020), "Intuitionistic fuzzy model for reliability management in wind turbine system", Applied Computing and Informatics. Vol. 16 No. 1/2, pp. 181-194. The original publication date for this paper was 12/05/2018.
}

Intuitionistic fuzzy model

Received 28 January 2018 Revised 28 April 2018 Accepted 8 May 2018 
$\mathrm{ACI}$

$16,1 / 2$

182
Since mechanical system is a group of interacting, interrelated, or interdependent components that form a complex and unified whole [7]. Detecting faults in such system have proven a difficult task [8], due to the dependency of its components on each other [9]. Faults in WT can occur in a number of components, like sensors or actuators parts, however, early detection of unexpected changes in the system, could save the WT from unforeseen hazards and improve its performance $[10,11]$ and reliability management.

Failure detection and estimation in mechanical system, is part of a decision-making process in many fields of discipline including engineering. Failure estimation provides the advanced information about faults that identifies the intensity of the system behavior. In the reliability study of wind turbine technology, different approaches and methods have been used, depending on the availability of data.

Some of the methods include; the use of a combined adaptive and parameter estimation schemes that assumes a set of possible faults affecting the dynamics of the wind turbine by Witczak et al. [12]. Odofin et al. [13] apply an eigenstructure assignment and genetic algorithm (GA) optimization method for robust fault estimation in wind turbine systems. Simani \& Farsoni [14], presents a robust fault diagnosis and fault-tolerant control schemes for Wind Turbines system by applying a data-driven and model-based approach, which is able to cope with unknown nonlinear systems and noisy measurements. Awedni \& Krichen [15], proposed a method for enhancing the rapidity and accuracy performance of fault estimation by using an adaptive fault diagnosis observer method for a DFIG based wind turbine system. Michos et al. [16], proposed a probabilistic safety assessment method which is based on Event-tree approach and Markov procedure for reliability and safety assessment of WT systems. Akwasi \& Dueñas-Osorio [17], proposed a closed-form method (Monte Carlo simulation) for evaluating reliability in WT system and associated failure consequences. $\mathrm{Su} \& \mathrm{Hu}$ [18], applied data mining techniques for analyzing the reliability characteristics of WT system.

Cristobal [19], applied a multi-criteria decision making (MCDM) model for renewable energy problems, which includes renewable energy planning, solar energy project, wind farm project, etc. Kahramen et al. [20] presents a comparative analysis using MCDM which is based on fuzzy Axiomatic design and fuzzy analytic hierarchy model for renewable energy alternative. Laska [21], presents various discussions on methods of multi-criteria analysis (MAUT, AHP, DEMATEL, ELECTRE, PROMETHEE and Borda ranking methods) and their rules of proceeding for accounting for decisions regarding the selection of wind farm location in NE Poland. Lee et al. [22], proposed a new multi-criterion decision-making (MCDM) model, based on the analytic hierarchy process (AHP) associated with benefits, opportunities, costs and risks (BOCR), for selection of a suitable wind farm project. Chen et al. [23] proposed a hybrid MCDM model which includes; decision-making trial and evaluation laboratory (DEMATEL) and DEMATEL-based analytic network process (DANP) based on geographical information systems (GIS) for improving the performance of solar farms. Bose and Chatteriee [24] presents a hybrid approach based on Fuzzy multiple MCDM techniques (Fuzzy Additive Ratio Assessment, Fuzzy Multi-Objective Optimization on the basis of Ratio Analysis and Group Decision-making method) with tactical viewpoint for supporting the recruitment process of wind turbine service technicians. A comprehensive detail of the methods are presented in Table 1.

The work and methods presented in [1,12-18] for fault diagnosis in wind turbine, are all based on the availability of research data (i.e. the acquisition of valid source information about the relevant selection of key characteristics and behaviours). While the MCDM methods ([19-24]), were mostly used for the selection and making of decisions for wind farms. However, in the event that there are limited research data or limited valid source of information for the failure detention assessment in the wind turbine system and if flexibility is required in the decision-making process, the above methods and approaches will 


\begin{tabular}{|c|c|c|}
\hline Authors & Methods for reliability assessment of WT systems & onistic \\
\hline Witczak et al. [12] & Combined adaptive and parameter estimation schemes & \\
\hline Odofin et al. [13] & Eigenstructure assignment and genetic algorithm (GA) optimization method & \\
\hline Simani \& Farsoni [14] & Data-driven and model-based approach & \\
\hline Awedni \& Krichen [15] & Adaptive fault diagnosis observer method & \\
\hline Michos et al. [16] & Event-tree approach and Markov procedure & \\
\hline $\begin{array}{l}\text { Akwasi \& Dueñas- } \\
\text { Osorio [17] }\end{array}$ & A closed-form method (Monte Carlo simulation) & 183 \\
\hline Su \& Hu [18] & $\begin{array}{l}\text { Data mining techniques are applied to analyze the reliability characteristics of } \\
\text { wind turbines }\end{array}$ & \\
\hline Cristobal [19] & Multi-criteria decision making (MCDM) model & \\
\hline Kahramen et al. [20] & Fuzzy Axiomatic design and fuzzy analytic hierarchy model & \\
\hline Laska [21] & $\begin{array}{l}\text { Integrated model of MAUT, AHP, DEMATEL, ELECTRE, PROMETHEE and } \\
\text { Borda ranking methods }\end{array}$ & \\
\hline Lee et al. [22] & $\begin{array}{l}\text { Analytic hierarchy process (AHP) and Benefits, opportunities, costs and risks } \\
\text { (BOCR) model }\end{array}$ & \\
\hline Chen et al. [23] & $\begin{array}{l}\text { Decision-making trial and evaluation laboratory (DEMATEL) and DEMATEL- } \\
\text { based analytic network process (DANP) based on geographical information } \\
\text { systems (GIS) }\end{array}$ & $\begin{array}{l}\text { Table } 1 . \\
\text { thods for reliability }\end{array}$ \\
\hline Bose and Chatteriee [24] & $\begin{array}{l}\text { Fuzzy Additive Ratio Assessment, Fuzzy Multi-Objective Optimization on basis of } \\
\text { Ratio Analysis and Group Decision-making method }\end{array}$ & $\begin{array}{r}\text { assessment of WT } \\
\text { systems. }\end{array}$ \\
\hline
\end{tabular}

automatically become invalid and ineffective. Hence, a new model which is based on a Triangular intuitionistic flexibility ranking and aggregating (TIFRA) model is proposed. The TIFRA which consist of an Induced triangular intuitionistic hybrid fuzzy weighted geometric (I-TIHFWG) operator, and a Flexibility ranking score function is used for failure detection and reliability management of the WT system. The main advantage of this new model is that it takes into account the flexibility concerns of the group of experts associated with the reliability management and prediction. As well as, reduces the complexity and uncertainty in using an expert assessment method by representing adequately all such complexity and uncertainty in a holistic manner using Triangular intuitionistic fuzzy number (TIFN) which is a more generalized platform for expressing imprecise, incomplete and inconsistent information [25]. Furthermore, a ranking sensitivity analysis of the attitudinal score function with respect to the attitudinal parameter is provided to address the ranking problem associated with the TIFN(s) [26].

In ranking TIFN, $\mathrm{Li}$ [27] introduced the score and accuracy function which to date is the most widely used method, and for converting TIFN into representative crisp value and for performing their comparison. These functions, however, cannot handle or account for the flexibility concerns of experts, since it assumes the flexibility concerns of each expert as neutral. Hence, it is unable to capture holistically all the information contained and associated with the TIFN.

The rest of this paper is organized as follows. In Section 2, the methodology which consists of the TIFN and the flexibility ranking score function, TIFNs aggregation operators and the TIFN in multi-criteria group decision-making (MCGDM) is presented. While in Section 3, a numerical case study of the wind Turbine is presented to demonstrate the effectiveness of the model. Finally, in Section 4 some concluding remarks are given.

\section{Methodology}

\subsection{TIFN and the flexibility ranking score function}

To define the fuzzy nature and complexity of the real world more comprehensively, Atanassov [28] introduced IFS, which is an extension of the traditional fuzzy set. 
Definition 1. If the IFS $A$ in $X=\{x\}$ is defined in the form [28],

$$
A=\left\{\left\langle x, \mu_{A}(x), v_{A}(x)\right\rangle \mid x \in X\right\}
$$

where $\mu_{A}: X \rightarrow[0,1]$, is the membership function and $v_{A}: X \rightarrow[0,1]$ the non-membership function, with the condition $0 \leq \mu_{A}(x)+v_{A}(x) \leq 1, \mu_{A}(x), v_{A}(x) \in[0,1], \forall x \in X$

For each $A$ in $\mathrm{X}$, we can compute the intuitionistic index of the element $\mathrm{x}$ in the set $A$, which is defined as follows:

$$
\pi_{A}(x)=1-\left(\mu_{A}(x)+v_{A}(x)\right)
$$

Definition 2. If the IFS $A$ in $X=\{x\}$ is defined fully in the form $A=\left\{\left\langle x, \mu_{A}(x)\right.\right.$, $\left.\left.v_{A}(x), \pi_{A}(x)\right\rangle \mid x \in X\right\}$, where $\mu_{A}: X \rightarrow[0,1], v_{A}: X \rightarrow[0,1]$ and $\pi_{A}: X \rightarrow[0,1]$. The different relations and operations for the IFS are [29,30];

(1) $A \cdot B=\left\{\left\langle x, \mu_{A}(x) \cdot \mu_{B}(x), v_{A}(x)+v_{B}(x)-v_{A}(x) \cdot v_{B}(x)\right\rangle \mid x \in X\right\} ;$

(2) $A+B=\left\{\left\langle x, \mu_{A}(x)+\mu_{B}(x)-\mu_{A}(x) \cdot \mu_{B}(x), v_{A}(x) \cdot v_{B}(x)\right\rangle \mid x \in X\right\}$;

(3) $\lambda A=\left\{\left\langle x, 1-\left(1-\mu_{A}(x)\right)^{\lambda},\left(v_{A}(x)\right)^{\lambda}\right\rangle \mid x \in X\right\}, \lambda>0$;

(4) $A^{\lambda}=\left\{\left\langle x,\left(\mu_{A}(x)\right)^{\lambda}, 1-\left(1-v_{A}(x)\right)^{\lambda}\right\rangle \mid x \in X\right\}, \lambda>0$;

(5) $A=B$ if and only if $\mu_{A}(x)=\mu_{B}(x)$ and $v_{A}(x)=v_{B}(x)$ for all $x \in X$;

(6) $A \leq B$ if and only if $\mu_{A}(x) \leq \mu_{B}(x)$ and $v_{A}(x) \leq v_{B}(x)$ for all $x \in X$.

Recently, the IFSs have been extended to the Triangular Intuitionistic Fuzzy Sets (TIFSs), with the characteristic membership and non-membership values represented with the TIFN [27]. The TIFN is therefore denoted as $\alpha^{\prime}=\left\langle\left([a, b, c] ; \mu_{\alpha}\right),\left([a, b, c] ; v_{\alpha}\right)\right\rangle$, when $\mu_{\alpha}=1$, and $v_{\alpha}=0, \alpha^{\prime}$, will change into the traditional triangular fuzzy number (TFN). Generally the TIFN $\alpha^{\prime}$ is defined as $\alpha^{\prime}=\left([a, b, c] ; \mu_{\alpha}, v_{\alpha}\right)$ for conveniences, with the membership function represented as:

$$
\mu_{\alpha}(x)=\left\{\begin{array}{cc}
\frac{(x-a) \mu_{\alpha}}{(b-a)} & (a \leq x<b), \\
\mu_{\alpha} & (x=b) \\
\frac{(c-x) \mu_{\alpha}}{c-b} & (b<x \leq c), \\
0 & \text { otherwise }
\end{array}\right.
$$

and the non-membership function as;

$$
v_{\alpha}(x)=\left\{\begin{array}{cc}
\frac{\left(b-x+v_{\alpha}\left(x-a^{\prime}\right)\right)}{\left(b-a^{\prime}\right)} & \left(a^{\prime} \leq x<b\right), \\
v_{\alpha} & (x=b) \\
\frac{\left(x-b+v_{\alpha}\left(c^{\prime}-x\right)\right)}{c^{\prime}-b} & \left(b<x \leq c^{\prime}\right), \\
0 & \text { otherwise }
\end{array}\right.
$$

where $0 \leq \mu_{\alpha} \leq 1 ; 0 \leq v_{\alpha} \leq 1 ; 0 \leq \mu_{\alpha}+v_{\alpha} \leq 1, a, b, c, a^{\prime}, c^{\prime} \in \mathrm{R}$. 
Definition 3. Let and $\alpha_{1}=\left(\left[a_{1}, b_{1}, c_{1}\right] ; \mu_{\alpha_{1}}, v_{\alpha_{1}}\right)$ and $\alpha_{2}=\left(\left[a_{2}, b_{2}, c_{2}\right] ; \mu_{\alpha_{2}}, v_{\alpha_{2}}\right)$ be two TIFN and $\lambda \leq 0$ then. The operational results for the two TIFNs are given in the theorem [31,32].

1. $\alpha_{1}+\alpha_{2}=\alpha_{2}+\alpha_{1}$

2. $\quad \alpha_{1} \otimes \alpha_{2}=\alpha_{2} \otimes \alpha_{1}$

3. $\lambda\left(\alpha_{1}+\alpha_{2}\right)=\lambda \alpha_{1}+\lambda \alpha_{2} \quad \lambda \geq 0$,

4. $\quad \lambda_{1} \alpha+\lambda_{2} \alpha=\left(\lambda_{1}+\lambda_{2}\right) \alpha \lambda_{1} \quad \lambda_{2} \geq 0$

5. $\quad \alpha^{\lambda_{1}} \otimes \alpha^{\lambda_{2}}=\alpha^{\lambda_{1}+\lambda_{2}} \lambda_{1} \quad \lambda_{2} \geq 0$

6. $\quad \alpha_{1}^{\lambda} \otimes \alpha_{2}^{\lambda}=\left(\alpha_{1} \otimes \alpha_{2}\right)^{\lambda} \quad \lambda \geq 0$

Definition 4. Let $\alpha_{1}=\left(\left[a_{1}, b_{1}, c_{1}\right] ; \mu_{\alpha_{1}}, v_{\alpha_{1}}\right)$ and $\alpha_{2}=\left(\left[a_{2}, b_{2}, c_{2}\right] ; \mu_{\alpha_{2}}, v_{\alpha_{2}}\right)$ be two TIFN, the Hamming distance between $\alpha_{1}$ and $\alpha_{2}$ is given as [33];

$$
\begin{aligned}
d\left(\alpha_{1}, \alpha_{2}\right)= & \frac{1}{6}\left[\left|\left(1+\mu_{\alpha_{1}}-v_{\alpha_{1}}\right) a_{1}-\left(1+\mu_{\alpha_{2}}-v_{\alpha_{2}}\right) a_{2}\right|+\mid\left(1+\mu_{\alpha_{1}}-v_{\alpha_{1}}\right) b_{1}\right. \\
& \left.-\left(1+\mu_{\alpha_{2}}-v_{\alpha_{2}}\right) b_{2}|+|\left(1+\mu_{\alpha_{1}}-v_{\alpha_{1}}\right) c_{1}-\left(1+\mu_{\alpha_{2}}-v_{\alpha_{2}}\right) c_{2} \mid\right]
\end{aligned}
$$

To rank the TIFN, Li [27] introduced the score and accuracy function which has become the most widely used method for ranking TIFNs, for converting TIFN into representative crisp value and for performing their comparison.

Definition 5. Let $\alpha_{1}^{\prime}=\left([a, b, c] ; \mu_{\alpha}, v_{\alpha}\right)$ be a TIFN. If the membership and non-membership functions are represented by the score function $S\left(\alpha^{\prime}\right)$ and accuracy function $H\left(\alpha^{\prime}\right)$ respectively, then $\alpha^{\prime}$ can be defined as follow [27];

$$
\begin{gathered}
S\left(\alpha^{\prime}\right)=\frac{(a+2 b+c) \mu_{\alpha}}{4} \\
H\left(\alpha^{\prime}\right)=\frac{(a+2 b+c)\left(1-v_{\alpha}\right)}{4}
\end{gathered}
$$

Let $\alpha_{1}^{\prime}$ and $\alpha_{2}^{\prime}$ be two TIFN. If $S\left(\alpha_{i}^{\prime}\right)=\frac{\left(\alpha_{i}+2 b_{i}+c_{i}\right) \mu_{\alpha_{i}}}{4}$ and $H\left(\alpha^{\prime}\right)=\frac{\left(\alpha_{i}+2 b_{i}+c_{i}\right)\left(1-v_{\alpha_{i}}\right)}{4}$ are the membership and non-membership functions of $\alpha^{\prime}$ then;

(1) If $S\left(\alpha_{1}^{\prime}\right)<S\left(\alpha_{2}^{\prime}\right)$ then $\alpha_{1}^{\prime}<\alpha_{2}^{\prime}$

(2) If $S\left(\alpha_{1}^{\prime}\right)=S\left(\alpha_{2}^{\prime}\right)$ and $H\left(\alpha_{1}^{\prime}\right)=H\left(\alpha_{2}^{\prime}\right)$, then $\alpha_{1}^{\prime}=\alpha_{2}^{\prime}$

(3) If $S\left(\alpha_{1}^{\prime}\right)=S\left(\alpha_{2}^{\prime}\right)$ and $H\left(\alpha_{1}^{\prime}\right)<H\left(\alpha_{2}^{\prime}\right)$, then $\alpha_{1}^{\prime}<\alpha_{2}^{\prime}$

Although the above score and accuracy functions are effective in converting TIFN into representative crisp value and for performing their comparison, however, they are unable to take into account the design stakeholder's and reliability experts flexibility concerns which is critical in the evaluation and prediction of failure in an engineering. To overcome this shortcoming, the flexibility ranking functions are developed from the traditional Li's score and accuracy functions.

Definition 6. Let $\alpha^{\prime}=\left([a, b, c] ; \mu_{\alpha}, v_{\alpha}\right)$ be a TIFN. If the membership and non-membership functions are represented by the flexibility score function $A S\left(\alpha^{\prime}\right)$ and flexibility accuracy function $A H\left(\alpha^{\prime}\right)$ respectively, and then $\alpha^{\prime}$ can be defined as follow; 


$$
\begin{aligned}
& A S\left(\alpha^{\prime}\right)=(\lambda) \frac{\left(a+2 b+c+e^{\lambda *} \mu_{\alpha}^{\lambda}\right)}{4} \\
& A H\left(\alpha^{\prime}\right)=(\lambda) \frac{(a+2 b+c)\left(1-v_{\alpha}\right)}{4}
\end{aligned}
$$

where $\lambda$ is the flexibility parameter of the ranking function.

Example 1. Let $\alpha^{\prime}=([0.2,0.3,0.5] ; 0.3,0.45)$. and $\alpha_{1}^{\prime}=([0.25,0.3,0.45] ; 0.4,0.5)$ be two triangular intuitionistic fuzzy set for two alternatives, then we select the desirable alternative in accordance with the flexibility score and accuracy function, when the flexibility parameter value $\lambda=0.5$.

Using Eqs. (8) and (9), $A S\left(\alpha^{\prime}\right)=0.275, A H\left(\alpha^{\prime}\right)=0.036$ while $A S\left(\alpha_{1}^{\prime}\right)=0.293$, $A H\left(\alpha_{1}^{\prime}\right)=0.033$, clearly from the ranking order depending on the expert's flexibility concerns and the operational properties in Definition 5, it follows that; $\alpha^{\prime}<\alpha_{1}^{\prime}$. Hence, the study can conclude that the flexibility ranking functions are able to characterize quantitatively the relations between the aggregated arguments.

\subsection{TIFNs aggregation operators}

Based on the flexibility ranking function of TIFNs, we present the TIHFWG operator and the induced TIHFWG (I-TIHFWG) operator. The definition of TIHFWG operator is given as follows;

Definition 7. Let $\alpha_{i}=\left(\left[a_{i}, b_{i}, c_{i}\right] ; \mu_{\alpha_{\sigma i}}, v_{\alpha_{\sigma i}}\right)$ for all $(i=1,2,3, \ldots, n)$ be a collection of Triangular Intuitionistic Fuzzy Numbers on $X$. The triangular intuitionistic hybrid fuzzy weighted geometric (TIHFWG) operator of dimension $\mathrm{n}$ is a mapping TIHFWG: $\Omega^{n} \rightarrow \Omega$, and associated with the weighting vector $\omega=\left(\omega_{1}, \omega_{2}, \omega_{3}, \cdots, \omega_{n}\right)^{T}$ to it, such that $\omega_{i} \in[0,1]$, $\sum_{i=1}^{n} \omega_{i}=1$, and is defined to aggregate a collection of intuitionistic fuzzy values $\left(\alpha_{1}, \alpha_{2}, \alpha_{3}, \cdots, \alpha_{n}\right),[32,34]$.

$$
\begin{aligned}
& \text { TIHFWG }\left(\alpha_{1}, \alpha_{2}, \alpha_{3}, \cdots, \alpha_{n}\right)=\omega_{1}\left(\alpha_{\sigma 1}\right) \otimes \omega_{2}\left(\alpha_{\sigma 2}\right) \otimes \omega_{3}\left(\alpha_{\sigma 3}\right) \ldots \otimes \omega_{n}\left(\alpha_{\sigma n}\right) \\
& =\left(\left[\prod_{i=1}^{n}\left(a_{\sigma i}\right)^{\omega_{i}}, \prod_{i=1}^{n}\left(b_{\sigma i}\right)^{\omega_{i}}, \prod_{i=1}^{n}\left(c_{\sigma i}\right)^{\omega_{i}}\right] ; \prod_{i=1}^{n}\left(\mu_{\alpha_{\sigma i}}\right)^{\omega_{i}}, 1-\prod_{i=1}^{n}\left(1-v_{\alpha_{\sigma i}}\right)^{\omega_{i}}\right)
\end{aligned}
$$

where $a_{\sigma i}$ is the $i$ th largest of the of $\alpha_{i}$. Especially, $\omega=\left(\frac{1}{n}, \frac{1}{n}, 1 / n\right)^{T}$, then the TIHFWG operator is reduced to the IHFWG operator.

The TIHFWG operator which is able to weights the intuitionistic fuzzy values, however, fails in weighing the induced ordering positions of the intuitionistic fuzzy values, in order to overcome this limitation, we develop the I-TIHFWG operator which is able to weights both the given intuitionistic fuzzy value and its induced ordering position.

Definition 8. An induced triangular intuitionistic hybrid fuzzy weighted geometric (I-TIHFWG) operator is defined as follows;

$$
\begin{aligned}
I & -\operatorname{TIHFWG}_{\omega, W}\left(\left\langle x_{1}, \alpha_{1}\right\rangle,\left\langle x_{2}, \alpha_{2}\right\rangle,\left\langle x_{3}, \alpha_{3}\right\rangle, \cdots,\left\langle x_{n}, \alpha_{n}\right\rangle\right) \\
& =\omega_{1}\left(\alpha_{\sigma 1}\right) \otimes \omega_{2}\left(\alpha_{\sigma 2}\right) \otimes \omega_{3}\left(\alpha_{\sigma 3}\right) \ldots \otimes \omega_{n}\left(\alpha_{\sigma n}\right) \\
& =\left(\left[\prod_{i=1}^{n}\left(a_{\sigma i}\right)^{\omega_{i}}, \prod_{i=1}^{n}\left(b_{\sigma i}\right)^{\omega_{i}}, \prod_{i=1}^{n}\left(c_{\sigma i}\right)^{\omega_{i}}\right] ; \prod_{i=1}^{n}\left(\mu_{\alpha_{\sigma i}}\right)^{\omega_{i}}, 1-\prod_{i=1}^{n}\left(1-v_{\alpha_{\alpha i}}\right)^{\omega_{i}}\right)
\end{aligned}
$$


where $a_{\sigma i}$ is the weighted intuitionistic fuzzy value $\left.\alpha_{i}\left(\alpha_{i}=n w_{i} \alpha_{i}, j=1,2,3, \ldots, n\right)\right)$ of the TIHFWG pair $\left\langle x_{1}, \alpha_{1}\right\rangle$ having the $i$ th largest $x_{i}\left(x_{i} \in[0,1]\right)$, and $x_{i}$ in $\left\langle x_{1}, \alpha_{1}\right\rangle$ is referred to as the order inducing variable and $\alpha_{i}$ is the intuitionistic fuzzy argument variable.

$w=\left(w_{1}, w_{2}, w_{3}, \ldots, w_{n}\right)^{T}$ is the weighting vector such that $w_{i} \in[0,1], \sum_{i=1}^{n} w_{i}=1$, $i=1,2,3, \ldots, n, \omega=\left(\omega_{1}, \omega_{2}, \omega_{3}, \ldots, \omega_{n}\right)^{T}$ is the weighting vector associated with the ITIHFWG operator with $\omega_{i} \in[0,1], \sum_{i=1}^{n} \omega_{i}=1$.

\subsection{TIFNs in multi-criteria group decision-making (MCGDM)}

Consider a MCGDM problem with a set of alternatives $A=\left\{A_{1}, A_{2}, A_{3}, \ldots, A_{m}\right\}$, and criteria $C=\left\{C_{1}, C_{2}, C_{3}, \ldots, C_{m}\right\}$. If the characteristics of the alternatives $A_{i}$ are assessed with respect to a criterion $C_{j}$ using a TIFN, then the membership and non-membership degree of the alternatives are represented as $A_{i} \in A$ while criteria with $C_{j} \in C$. In using TIFNs in the multi-criteria decision-making, the study intends to select the best alternative according to the intuitionistic fuzzy decision matrix $R^{k}\left(\alpha_{\mathrm{ij}}\right)(k=1,2,3, \ldots, l)$ when the attribute weights are known. The proposed steps for solving the MCGDM problems when the values are expressed in TIFN are given below.

Step 1: Organize a group of experts $\operatorname{DM}^{k}(k=1,2,3, \ldots, l)$ with sufficient knowledge of the WT system to express their individual evaluation or preference to the set of alternatives $A=\left\{A_{1}, A_{2}, A_{3}, \ldots, A_{m}\right\}(i=1,2, \ldots, m)$ with respect to the failure criteria $C=\left\{C_{1}, C_{2}, C_{3}, \ldots, C_{m}\right\}(j=1,2, \ldots, n)$ using the information in Table 2, to obtain the intuitionistic fuzzy decision matrix $R^{k}=\left(r_{i}^{k}\right)_{m \times n}$.

$$
R^{k}=\left[\begin{array}{cccc}
\left(\left[x_{11}, y_{11}, z_{11}\right] ; \mu_{11}, v_{11}\right) & \cdots & \cdots & \left(\left[x_{1 n}, y_{1 n}, z_{1 n}\right] ; \mu_{1 n}, v_{1 n}\right) \\
\left(\left[x_{21}, y_{21}, z_{21}\right] ; \mu_{21}, v_{21}\right) & \cdots & \cdots & \left(\left[x_{2 n}, y_{2 n}, z_{2 n}\right] ; \mu_{2 n}, v_{2 n}\right) \\
\vdots & \vdots & \ddots & \vdots \\
\vdots & \vdots & \ddots & \vdots \\
\left(\left[x_{m 1}, y_{m 1}, z_{m 1}\right] ; \mu_{m 1}, v_{m 1}\right) & \cdots & \cdots & \left(\left[x_{m n}, y_{m n}, z_{m n}\right] ; \mu_{m n}, v_{m n}\right)
\end{array}\right]
$$

Step 2: With the information given in the matrix $R^{k}$, the TIHFWG operator is used to aggregate all the decision matrices $R^{k}(k=1,2,3, \ldots, l)$ into a collective decision matrix $R=\left(a_{\mathrm{ij}}\right)_{m \times n}$.

$$
\begin{aligned}
R & =\left(\left[a_{i}^{k}, a_{i}^{k}, a_{i}^{k}\right] ; \mu_{r_{i}^{k}}, v_{r_{i}^{k}}\right)=\operatorname{TIHFWG} G_{\omega}\left(\alpha_{1}, \alpha_{2}, \alpha_{3}, \ldots, \alpha_{n}\right) \\
& =\left(\left[\prod_{i=1}^{n}\left(a_{i}^{k}\right)^{w_{i}}, \prod_{i=1}^{n}\left(a_{i}^{k}\right)^{w_{i}}, \prod_{i=1}^{n}\left(a_{i}^{k}\right)^{w_{i}}\right] ; \prod_{i=1}^{n}\left(\mu_{r_{i}^{k}}\right)^{w_{i}}, 1-\prod_{i=1}^{n}\left(1-v_{r_{i}^{k}}\right)^{w_{i}}\right)
\end{aligned}
$$

where $w=\left(w_{1}, w_{2}, w_{3}, \ldots, w_{n}\right)^{T}$ is the weighting vector of the $D M^{k}$.

\begin{tabular}{ll}
\hline Linguistic terms & TIFNs \\
\hline Bad (L) & $([0.10,0.90,0.2] ; 0.4,0.4)$ \\
Unimportant $(U I)$ & $([0.20,0.80,0.2] ; 0.4,0.1)$ \\
Good $(G)$ & $([0.30,0.60,0.1] ; 0.4,0.3)$ \\
Very Good $(V G)$ & $([0.60,0.30,0.1] ; 0.5,0.2)$ \\
Very Important $(V I)$ & $([0.80,0.10,0.1] ; 0.6,0.1)$ \\
Highly Important $(H I)$ & $([0.90,0.10,0.2] ; 0.7,0.1)$
\end{tabular}

Intuitionistic fuzzy model

\section{,}


$\mathrm{ACI}$

$16,1 / 2$

\section{8}

Step 3: Using the information in Step 2, $\left(R=\left(a_{i j}\right)_{m \times n}\right)$, the I-TIHFWG operator is used to derive the overall preference values $r_{i}(i=1,2,3, \ldots, l)$, which is referred to as the collective comprehensive value $r_{i}$ of the alternatives $A_{i}$.

$$
\begin{aligned}
r_{i} & =\left(\left[r_{i}^{k}, r_{i}^{k}, r_{i}^{k}\right] ; \mu_{r_{i}^{k}}, v_{r_{i}^{k}}\right)=I-\operatorname{TIHFWG} G_{w}\left(\left\langle x_{1}, \alpha_{1}\right\rangle,\left\langle x_{2}, \alpha_{2}\right\rangle, \ldots,\left\langle x_{n}, \alpha_{n}\right\rangle\right) \\
& =\left(\left[\prod_{i=1}^{n}\left(r_{i}^{k}\right)^{w_{i}}, \prod_{i=1}^{n}\left(r_{i}^{k}\right)^{w_{i}}, \prod_{i=1}^{n}\left(r_{i}^{k}\right)^{w_{i}}\right] ; \prod_{i=1}^{n}\left(\mu_{r_{i}^{k}}\right)^{w_{i}}, 1-\prod_{i=1}^{n}\left(1-v_{r_{i}^{k}}\right)^{w_{i}}\right)
\end{aligned}
$$

where $w=\left(w_{1}, w_{2}, w_{3}, \ldots, w_{n}\right)^{T}$ is the weighting vector of the attributes.

Step 4: Calculate the flexibility scores function $A S\left(r_{i}\right)(i=1,2, \ldots, n)$ and flexibility accuracy function $A H\left(r_{i}\right)(i=1,2, \ldots, n)$ for the membership and non-membership functions.

$$
\begin{aligned}
& A S\left(\alpha^{\prime}\right)=(\lambda) \frac{\left(a+2 b+c+e^{\lambda} * \mu_{\alpha}^{\lambda}\right)}{4} \\
& A H\left(\alpha^{\prime}\right)=(\lambda) \frac{(a+2 b+c)\left(1-v_{\alpha}\right)}{4}
\end{aligned}
$$

Step 5: Rank the alternatives by the value. Make a sensitivity analysis with respect to the flexibility concerns.

Step 6: End

\section{Application of the proposed model for reliability management in the WT system}

In this section, the proposed model is applied for failure detention and for reliability management of a WT System.

Numerical Case Study: Faults in WT can occur in a number of components, like sensors and in the actuator parts, however, early detection of unexpected changes in the system, could save the WT from unforeseen hazards and improve its performance $[10,11]$ and reliability management.

Criteria to evaluate the faults or root cause of failure in the different components of the Case WT system have been investigated and obtained through extended consultation from a group of experts $\left(E_{1}, E_{2}, E_{3}\right.$, and $\left.E_{4}\right)$ with the weight vector $w=(0.2 ; 0.3 ; 0.35 ; 0.15)^{T}$ respectively, the experts are chosen based on their expertise in reliability management of WT systems, this is in line with work in literatures [35-37]. They were asked to rate the relevance, accuracy and adequacy of the criteria and to confirm 'content validity' with regards to the operation of the WT system. The failure criterion includes Chance of failure (O), Non-detection of Failures (D), Severity (S) maintainability $(\mathrm{M})$ and Economic cost $(\mathrm{EC})$ and they have been assigned the following weight vector $\omega=(0.1848 ; 0.2217 ; 0.1617 ; 0.2100 ; 0.2217)^{T}$, respectively.

The operational component parts of the sensors and actuator that have investigated in this study includes; the Vibration sensor for gear box monitoring $\left(A_{1}\right)$, oil level sensor tilt sensors for tower installation and accelerometers for tower sway $\left(\mathrm{A}_{2}\right)$, Pressure sensor for blade monitoring $\left(\mathrm{A}_{3}\right)$, and Pitch actuator $\left(\mathrm{A}_{4}\right)$. Using the assessment report from the group of experts, the root cause of failure and the area where the failure is most likely to affect with respect to the failures criteria is evaluated and detected using the proposed model. Details of the evaluation steps are given below, staring with the rating of the WT system by the experts $\left(E_{1}, E_{2}, E_{3}\right.$, and $\left.E_{4}\right)$ as shown in Tables 3-6. 
Following the algorithm of the proposed approach in Section 4, the failure mode alternatives are evaluated with respect to the criteria. Using the TIHFWG operator, the Expert's preference judgments $R^{k}(k=1,2,3, \ldots, l)$ are aggregated to form the aggregated expert's decision matrix $R=\left(r_{i j}\right)_{m \times n}$, the result of the aggregation is shown in Table 7 .
Intuitionistic fuzzy model

\begin{tabular}{llllll}
\hline$A_{i}$ & $C_{1}$ & $C_{2}$ & $C_{3}$ & $C_{4}$ & $C_{5}$ \\
\hline$A_{1}$ & $([0.26,0.50,0.73] ;$ & $([0.36,0.54,0.77] ;$ & $([0.24,0.41,0.56] ;$ & $([0.37,0.55,0.76] ;$ & $([0.32,0.48,0.66] ;$ \\
& $0.5,0.4)$ & $0.6,0.4)$ & $0.6,0.2)$ & $0.4,0.5)$ & $0.5,0.3)$ \\
$A_{2}$ & $([0.33,0.50,0.83] ;$ & $([0.31,0.48,0.77] ;$ & $([0.42,0.54,0.73] ;$ & $([0.39,0.59,0.86] ;$ & $([0.28,0.44,0.63] ;$ \\
& $0.7,0.1)$ & $0.5,0.3)$ & $0.7,0.3)$ & $0.3,0.5)$ & $0.4,0.6)$ \\
$A_{3}$ & $([0.26,0.41,0.62] ;$ & $([0.31,0.48,0.69] ;$ & $([0.48,0.61,0.81] ;$ & $([0.28,0.39,0.81] ;$ & $([0.32,0.48,0.71] ;$ \\
& $0.5,0.3)$ & $0.6,0.3)$ & $0.4,0.3)$ & $0.4,0.2)$ & $0.5,0.2)$ \\
$A_{4}$ & $([0.40,0.58,0.93] ;$ & $([0.36,0.48,0.77] ;$ & $([0.30,0.41,0.56] ;$ & $([0.24,0.44,0.60] ;$ & $([0.47,0.59,0.78] ;$ \\
& $0.6,0.2)$ & $0.7,0.2)$ & $0.8,0.1)$ & $0.6,0.3)$ & $0.7,0.2)$
\end{tabular}

\begin{tabular}{llllll}
\hline$A_{i}$ & $C_{1}$ & $C_{2}$ & $C_{3}$ & $C_{4}$ & $C_{5}$ \\
\hline$A_{1}$ & $([0.23,0.43,0.71] ;$ & $([0.32,0.42,0.68] ;$ & $([0.25,0.55,0.91] ;$ & $([0.32,0.45,0.57] ;$ & $([0.17,0.31,0.52] ;$ \\
& $0.7,0.1)$ & $0.8,0.2)$ & $0.5,0.4)$ & $0.5,0.4)$ & $0.6,0.3)$ \\
$A_{2}$ & $([0.35,0.50,0.80] ;$ & $([0.26,0.48,0.68] ;$ & $([0.25,0.44,1.00] ;$ & $([0.45,0.53,0.61] ;$ & $([0.36,0.54,0.70] ;$ \\
& $0.5,0.3)$ & $0.7,0.2)$ & $0.6,0.3)$ & $0.4,0.3)$ & $0.8,0.1)$ \\
$A_{3}$ & $([0.29,0.50,0.71] ;$ & $([0.37,0.54,0.76] ;$ & $([0.33,0.55,0.91] ;$ & $([0.43,0.52,0.63] ;$ & $([0.44,0.54,0.71] ;$ \\
& $0.6,0.2)$ & $0.5,0.3)$ & $0.7,0.2)$ & $0.6,0.2)$ & $0.6,0.4)$ \\
$A_{4}$ & $([0.41,0.57,0.80] ;$ & $([0.42,0.54,0.76] ;$ & $([0.25,0.44,0.76] ;$ & $([0.43,0.49,0.63] ;$ & $([0.46,0.57,0.71] ;$ \\
& $0.8,0.2)$ & $0.6,0.1)$ & $0.5,0.3)$ & $0.5,0.1)$ & $0.5,0.3)$
\end{tabular}

Table 3.

TIFN decision matrix by E1.

\begin{tabular}{llllll}
\hline$A_{i}$ & $C_{1}$ & $C_{2}$ & $C_{3}$ & $C_{4}$ & $C_{5}$ \\
\hline$A_{1}$ & $([0.30,0.42,0.75] ;$ & $([0.35,0.50,0.79] ;$ & $([0.29,0.45,0.69] ;$ & $([0.39,0.48,0.64] ;$ & $([0.44,0.53,0.65] ;$ \\
& $0.7,0.2)$ & $0.4,0.4)$ & $0.7,0.2)$ & $0.3,0.4)$ & $0.7,0.1)$ \\
$A_{2}$ & $([0.36,0.63,0.94] ;$ & $([0.29,0.50,0.99] ;$ & $([0.37,0.62,0.92] ;$ & $([0.34,0.42,0.59] ;$ & $([0.39,0.51,0.65] ;$ \\
& $0.5,0.4)$ & $0.7,0.3)$ & $0.6,0.3)$ & $0.6,0.3)$ & $0.5,0.3)$ \\
$A_{3}$ & $([0.36,0.49,0.75] ;$ & $([0.23,0.43,0.69] ;$ & $([0.37,0.53,0.81] ;$ & $([0.47,0.60,0.74] ;$ & $([0.35,0.48,0.64] ;$ \\
& $0.6,0.3)$ & $0.5,0.2)$ & $0.6,0.2)$ & $0.5,0.3)$ & $0.6,0.3)$ \\
$A_{4}$ & $([0.24,0.42,0.66] ;$ & $([0.29,0.57,0.89] ;$ & $([0.22,0.36,0.69] ;$ & $([0.30,0.48,0.65] ;$ & $([0.38,0.47,0.62] ;$ \\
& $0.6,0.2)$ & $0.8,0.1)$ & $0.5,0.4)$ & $0.4,0.3)$ & $0.5,0.5)$
\end{tabular}

Table 4.

TIFN decision matrix by E2.

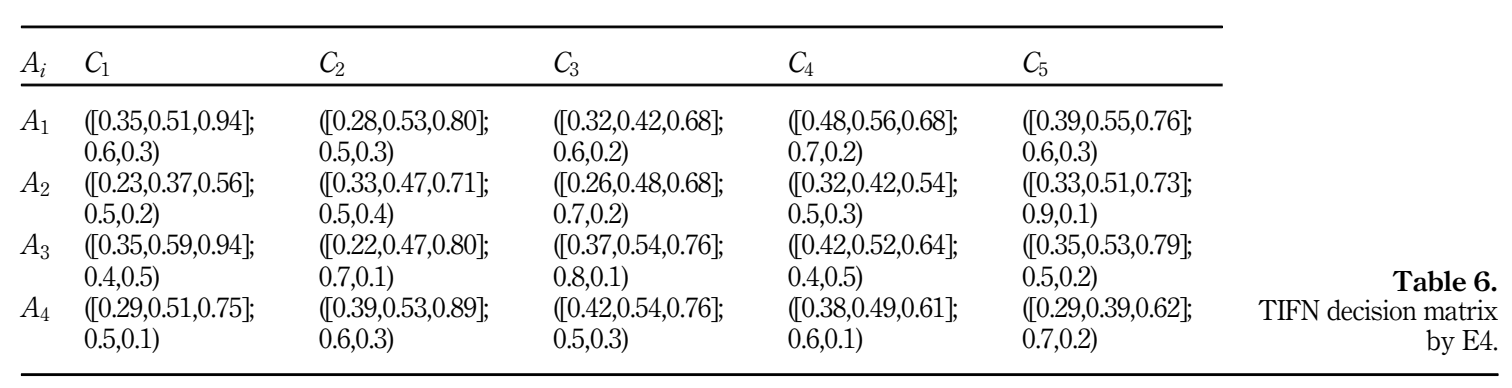

Table 5.

TIFN decision matrix by E3. 
$\mathrm{ACI}$

$16,1 / 2$

190

Using the I-TIHFWGA operator, when the weight vector associated with the criteria is given as; $\omega=(0.1848 ; 0.2217 ; 0.1617 ; 0.2100 ; 0.2217)^{T}$. The comprehensive evaluation for the four failure mode alternatives is achieved as shown in Table 8. For the different values of the parameter $\lambda$ which is used to represent and express the flexibility concerns of the experts when evaluating and managing the reliability of the WT system has be given in Table 9 .

Discussion of Result: From the ranking result of the four failure modes assessment, the study can conclude therefore that the most important area affected by failure with respect to the failure criteria used, includes; oil level sensor tilt sensors for tower installation and accelerometers for tower sway $\left(A_{2}\right)$, Pressure sensor for blade monitoring $\left(A_{3}\right)$, and Pitch actuator $\left(\mathrm{A}_{4}\right)$.

Table 7.

Aggregated experts reliability information for the system.

\begin{tabular}{llllll}
\hline$A_{i}$ & $C_{1}$ & $C_{2}$ & $C_{3}$ & $C_{4}$ & $C_{5}$ \\
\hline \multirow{2}{*}{$A_{1}$} & $([0.28,0.45,0.76] ;$ & $([0.33,0.49,0.75] ;$ & $([0.27,0.46,0.70] ;$ & $([0.38,0.50,0.65] ;$ & $([0.31,0.44,0.62] ;$ \\
& $0.64,0.23)$ & $0.55,0.33)$ & $0.60,0.27)$ & $0.42,0.40)$ & $0.61,0.24)$ \\
$A_{2}$ & $([0.33,0.52,0.81] ;$ & $([0.29,0.49,0.80] ;$ & $([0.32,0.52,0.86] ;$ & $([0.38,0.48,0.63] ;$ & $([0.35,0.50,0.67] ;$ \\
& $0.53,0.29)$ & $0.62,0.29)$ & $0.63,0.30)$ & $0.45,0.35)$ & $0.60,0.30)$ \\
$A_{3}$ & $([0.31,0.49,0.73] ;$ & $([0.28,0.48,0.73] ;$ & $([0.38,0.55,0.83] ;$ & $([0.41,0.52,0.70] ;$ & $([0.37,0.53,0.70] ;$ \\
& $0.54,0.31)$ & $0.55,0.24)$ & $0.61,0.21)$ & $0.49,0.29)$ & $0.56,0.30)$ \\
$A_{4}$ & $([0.32,0.51,0.76] ;$ & $([0.35,0.54,0.82] ;$ & $([0.27,0.42,0.69] ;$ & $([0.33,0.48,0.63] ;$ & $([0.40,0.51,0.68] ;$ \\
& $0.64,0.19)$ & $0.68,0.15)$ & $0.55,0.30)$ & $0.49,0.22)$ & $0.56,0.35)$
\end{tabular}

\begin{tabular}{ll}
\hline$F$ & Comprehensive value \\
\hline$A_{1}$ & $([0.313,0.468,0.693] ; 0.555,0.298)$ \\
$A_{2}$ & $([0.332,0.501,0.743] ; 0.563,0.305)$ \\
$A_{3}$ & $(0.345,0.510,0.732] ; 0.546,0.271)$ \\
$A_{4}$ & $([0.337,0.491,0.714] ; 0.582,0.244)$ \\
\hline
\end{tabular}

Table 9.

The ranking of all the failure modes with respect to the

Flexibility parameter.

\begin{tabular}{|c|c|c|c|c|c|c|c|c|c|c|}
\hline \multirow[b]{2}{*}{$\lambda$} & \multicolumn{2}{|c|}{$A_{1}$} & \multicolumn{2}{|c|}{$\mathrm{A}_{2}$} & \multicolumn{2}{|c|}{$\mathrm{A}_{3}$} & \multicolumn{2}{|c|}{$\mathrm{A}_{4}$} & \multirow[b]{2}{*}{ Ranking } & \multirow[b]{2}{*}{$\mathrm{F}$} \\
\hline & AS & $\mathrm{AH}$ & AS & $\mathrm{AH}$ & AS & $\mathrm{AH}$ & AS & $\mathrm{AH}$ & & \\
\hline 0.1 & 0.075 & 0.034 & 0.078 & 0.036 & 0.078 & 0.038 & 0.077 & 0.038 & $A_{3}>A_{2}>A_{4}>A_{1}$ & \\
\hline 0.2 & 0.151 & 0.068 & 0.15 & 0.072 & 0.1 & $0.0^{7}$ & & 0.07 & $A_{3}>A_{2}$ & \\
\hline 0.3 & 0.231 & 0.1 & 0.2 & 0.108 & & 0.1 & & 0.115 & $>A_{4}>A_{1}$ & \\
\hline 0.4 & 0.312 & 0.136 & 0.326 & 0.144 & 0.327 & 0.1 & 0.323 & 0.154 & $A_{3}>A_{2}>A_{4}>A_{1}$ & \\
\hline 0.5 & 0.396 & 0.17 & 0.41 & 0.180 & & 0.191 & & 0.192 & & \\
\hline 0.6 & 0.483 & 0.2 & 0.5 & 0.216 & & 0.2 & & 0.231 & $A_{2}>A_{3}>A_{4}>A_{1}$ & \\
\hline 0.7 & 0.573 & 0.239 & 0.599 & 0.253 & 0.597 & 0.267 & 0.597 & 0.269 & $A_{2}>A_{4}>A_{3}>A_{1}$ & \\
\hline 0.8 & 0.667 & 0.273 & 0.696 & 0.289 & 0.693 & 0.306 & 0.695 & 0.307 & $A_{2}>A_{4}>A_{1}>A_{3}$ & \\
\hline 0.9 & 0.763 & 0.307 & 0.797 & 0.325 & 0.792 & 0.344 & 0.797 & 0.346 & $A_{4}>A_{2}>A_{3}>A_{1}$ & \\
\hline
\end{tabular}


These components have the highest risk factors depending on the flexibility concerns of the evaluating experts. The main advantage of the result presented using the proposed approach is that the flexibility concerns of the experts are fully accounted for. Also the result proves that the flexibility concerns of the evaluating experts can indeed affect the final reliability decisions and result. Furthermore, the result obtained from the proposed have proved that even when there are limited primary research data and valid source of information, expert-based knowledge/opinion can be used for failure detection and reliability management in WT systems as well as in other mechanical systems.

Comparison of Result: To prove the effectiveness of the model it is compared with the MCGDM approach which is based on the triangular intuitionistic fuzzy aggregation operator originally proposed by $\mathrm{Li}(2010)$ as shown in Tables 10 and 11.

From the comparison analysis, the study can conclude that the proposed approach is effective, feasible and rational. Since the results of the triangular intuitionistic fuzzy aggregation operator proposed by $\mathrm{Li}(2010)$ is in agreement with the results of the proposed model as shown in Table 12.

\begin{tabular}{rlrll}
\hline$\lambda=0.1$ & $\lambda=0.2$ & $\lambda=0.3$ & $\lambda=0.4$ & $\lambda=0.5$ \\
\hline
\end{tabular}

$A_{1} \quad Z\left(S_{1}, 0.1\right)=0.035 \quad Z\left(S_{1}, 0.2\right)=0.071 \quad Z\left(S_{1}, 0.3\right)=0.108 \quad Z\left(S_{1}, 0.4\right)=0.147 \quad Z\left(S_{1}, 0.5\right)=0.188$

$A_{2} \quad Z\left(S_{1}, 0.1\right)=0.039 \quad Z\left(S_{1}, 0.2\right)=0.080 \quad Z\left(S_{1}, 0.3\right)=0.123 \quad Z\left(S_{1}, 0.4\right)=0.168 \quad Z\left(S_{1}, 0.5\right)=0.215$

$A_{3} \quad Z\left(S_{1}, 0.1\right)=0.042 \quad Z\left(S_{1}, 0.2\right)=0.086 \quad Z\left(S_{1}, 0.3\right)=0.132 \quad Z\left(S_{1}, 0.4\right)=0.180 \quad Z\left(S_{1}, 0.5\right)=0.232$

$A_{4} \quad Z\left(S_{1}, 0.1\right)=0.040 \quad Z\left(S_{1}, 0.2\right)=0.081 \quad Z\left(S_{1}, 0.3\right)=0.125 \quad Z\left(S_{1}, 0.4\right)=0.171 \quad Z\left(S_{1}, 0.5\right)=0.219$
Intuitionistic fuzzy model

Table 10. The DMs preference information with the alternating the parameter.

\begin{tabular}{llll}
\hline$\lambda$ & Ranking & $\mathrm{F}$ & \\
\hline 0.1 & $A_{3}>A_{4}>A_{2}>A_{1}$ & $A_{3}$ & Table 11. \\
0.2 & $A_{3}>A_{4}>A_{2}>A_{1}$ & $A_{3}$ & The ranking of all the \\
0.3 & $A_{3}>A_{4}>A_{2}>A_{1}$ & $A_{3}$ & failure modes with \\
0.4 & $A_{3}>A_{4}>A_{2}>A_{1}$ & $A_{3} \mathrm{C}$ & respect to the \\
0.5 & $A_{3}>A_{4}>A_{2}>A_{1}$ & $A_{3}$ & Flexibility parameter. \\
\hline
\end{tabular}

\begin{tabular}{|c|c|c|c|c|c|}
\hline$\lambda$ & $\begin{array}{l}\text { Proposed Model } \\
\text { Ranking }\end{array}$ & $\mathrm{F}$ & $\begin{array}{l}\text { Model by Li (2010) } \\
\text { Ranking }\end{array}$ & $\mathrm{F}$ & \\
\hline $\begin{array}{l}0.1 \\
0.2 \\
0.3 \\
0.4 \\
0.5\end{array}$ & $\begin{array}{l}A_{3}>A_{4}>A_{2}>A_{1} \\
A_{3}>A_{4}>A_{2}>A_{1} \\
A_{3}>A_{4}>A_{2}>A_{1} \\
A_{3}>A_{4}>A_{2}>A_{1} \\
A_{3}>A_{4}>A_{2}>A_{1}\end{array}$ & $\begin{array}{l}A_{3} \\
A_{3} \\
A_{3} \\
A_{3} \\
A_{3}\end{array}$ & $\begin{array}{l}A_{3}>A_{4}>A_{2}>A_{1} \\
A_{3}>A_{4}>A_{2}>A_{1} \\
A_{3}>A_{4}>A_{2}>A_{1} \\
A_{3}>A_{4}>A_{2}>A_{1} \\
A_{3}>A_{4}>A_{2}>A_{1}\end{array}$ & $\begin{array}{l}A_{3} \\
A_{3} \\
A_{3} \\
A_{3} \\
A_{3}\end{array}$ & $\begin{array}{l}\text { Table } 12 . \\
\text { The ranking of all the } \\
\text { failure modes with } \\
\text { respect to the } \\
\text { Flexibility parameter. }\end{array}$ \\
\hline
\end{tabular}


$\mathrm{ACI}$

$16,1 / 2$

192

\section{Conclusion}

In this paper, a Triangular intuitionistic flexibility ranking and aggregating (TIARA) model which is based on an Induced triangular intuitionistic hybrid fuzzy weighted geometric (I-TIHFWG) operator and an flexibility rank score function has been proposed for failure detection and reliability management of WT systems. The advantages of this model include; its ability to account for the flexibility concerns the experts associated with the evaluation and management of the reliability of the WT system. It helps in reducing the complexity in using expert assessment method by representing holistically all the complexity and uncertainty using the Triangular intuitionistic fuzzy number (TIFN) which is a more generalized platform for expressing imprecise and inconsistent information and finally. It provides an opportunity for carrying out a sensitivity analysis using the flexibility score function (flexibility parameter), thereby addressing the ranking problem normally associated with the TIFN(s).

To demonstrate the effectiveness, feasibility, and rationality of the proposed model, it has been compared with the similar computational model in literature. In the future, I will continue working on the application of the proposed model in other domain.

\section{References}

[1] S. Odofin, E. Bentley, D. Aikhuele, Robust fault estimation for wind turbine energy via hybrid systems, Renew. Energy (2017), pp. 1-13 (in press).

[2] D.O. Aikhuele, F.B.M. Turan, Intuitionistic fuzzy-based model for failure detection, Springerplus 1938 (5) (2016) 1-15.

[3] D.O. Aikhuele, F.M. Turan, A modified exponential score function for troubleshooting an improved locally made Offshore Patrol Boat engine, J. Mar. Eng. Technol., no. February, 2017.

[4] A. Kusiak, W. Li, The prediction and diagnosis of wind turbine faults, Renew. Energy 36 (2011) $6-23$.

[5] B.S. Nivedh, Major failures in the Wind Turbine components and the Importance of Periodic Inspection, http://www.windinsider.com/, 2014, pp. 32-36.

[6] H. Alwi, C. Edwards, C.P. Tan, Fault Tolerant Control and Fault Detection and Isolation, Springer-Verlag London Limited, London, 2011.

[7] V. Anderson, L. Johnson, Systems Thinking Basics. From Concepts to Causal Loops. Mass Pegasus Comm., Inc., Waltham, 1997.

[8] A. Balin, H. Demirel, A. Fuat, A hierarchical structure for ship diesel engine trouble-shooting problem using Fuzzy Ahp and Fuzzy Vikor hybrid methods, Brodogradnja 66 (1) (2014) 54-65.

[9] D.O. Aikhuele, F.M. Turan, S.M. Odofin, R.H. Ansah, Interval-valued intuitionistic fuzzy TOPSISbased model for troubleshooting marine diesel engine auxiliary system, Int. J. Marit. Eng. A 159 (2016) 1-8.

[10] Z. Gao, C. Cecati, S.X. Ding, A survey of fault diagnosis and fault-tolerant techniques-part I: fault diagnosis with model-based and signal-based approaches, IEEE Trans. Ind. Electron. 62 (6) (2015) 3757-3767.

[11] D.O. Aikhuele, S. Sorooshian, R.H. Ansah, F.M. Turan, Application of intuitionistic fuzzy topsis model for troubleshooting an offshore patrol boat engine, Polish Marit. Res. 24 (94) (2017) 68-76.

[12] M. Witczak, D. Rotondo, V. Puig, F. Nejjari, M. Pazera, Fault estimation of wind turbines using combined adaptive and parameter estimation schemes, Int. J. Adapt. Control Signal Process. 2017, pp. $1-19$.

[13] S. Odofin, Z. Gao, K. Sun, Robust fault estimation in wind turbine systems using GA optimisation, in: 13th International Conference on Industrial Informatics (INDIN), 2015 IEEE Cambridge, UK, 2015, pp. 580-585. 
[14] S. Simani, S. Farsoni, Fault Diagnosis and Sustainable Control of Wind Turbines, first ed., Butterworth-Heinemann, 2018.

[15] O. Awedni, L. Krichen L, Adaptive observer-based fault estimation for a DFIG based wind turbine system, in: 11th International Conference on Ecological Vehicles and Renewable Energies (EVER), Monte Carlo, 2016, 2016, pp. 1-7.

[16] D. Michos, E. Dialynas, P. Vionis, Reliability and safety assessment of wind turbines control and protection systems, Wind Eng. 26 (6) (2002) 359-369.

[17] A.F. Mensah, L. Dueñas-Osorio, A closed-form technique for the reliability and risk assessment of wind turbine systems, Energies 5 (6) (2012) 1734-1750.

[18] C. Su, Z. Hu, Reliability assessment for Chinese domestic wind turbines based on data mining techniques, Wind Energy 21 (3) (2018) 198-209.

[19] S. Cristobal, Multi-criteria decision-making in the selection of renewable energy project in Spain; The VIKOR method, Renew. Energy 36 (2011) 498-502.

[20] C. Kahraman, I. Kaya, S. Cebi, A comparative analysis for Multiattribute selection among renewable energy alternatives using fuzzy Axiomatic design and fuzzy analytic hierarchy process, Energy 34 (2009) pp. 1603-1616.

[21] G. Laska, Wind energy and multi-criteria analysis in making decisions on the location of wind farms, Procedia Eng. 182 (2017) 418-424.

[22] A.H.I. Lee, H.H. Chen, H.Y. Kang, Multi-criteria decision making on strategic selection of wind farms, Renew. Energy 34 (1) (2009) 120-126.

[23] C.R. Chen, C.C. Huang, H.J. Tsuei, A hybrid MCDM model for improving GIS-based solar farms site selection, Int. J. Photoenergy 2014 (2014) 1-9.

[24] G.K. Bose, N.C. Chatterjee, Fuzzy hybrid MCDM approach for selection of wind turbine service technicians, Manage. Sci. Lett. 6 (2016) 1-18.

[25] D.F. Li, J.X. Nan, M.J. Zhang, A ranking method of triangular intuitionistic fuzzy numbers and application to decision making, Int. J. Comput. Intell. Syst. 3 (5) (2010) 522-530.

[26] K. Arun Prakash, M. Suresh, S. Vengataasalam, A new approach for ranking of intuitionistic fuzzy numbers using a centroid concept, Math. Sci. 10 (4) (2016) 177.

[27] D.-F. Li, A ratio ranking method of triangular intuitionistic fuzzy numbers and its application to MADM problems, Comput. Math. Appl. 60 (6) (2010) 1557-1570.

[28] K.T. Atanassov, Intuitionistic fuzzy sets, Fuzzy Sets Syst. 20 (1) (1986) 87-96.

[29] D.O. Aikhuele, F.M. Turan, An exponential-related function for decision-making in engineering and management, Open Eng. 7 (2017) 153-160.

[30] D.O. Aikhuele, F.B.M. Turan, An improved methodology for multi-criteria evaluations in the shipping industry, Brodogradnja/Shipbuilding 67 (3) (2016) 59-72.

[31] X. Zhang, P. Liu, Method for aggregating triangular fuzzy intuitionistic fuzzy information and its application to decision making, Technol. Econ. Dev. Econ. 16 (2) (2010) 280-290.

[32] C. Liang, S. Zhao, J. Zhang, Aggregation operators on triangular intuitionistic fuzzy numbers and its application to multi-criteria decision making problems, Found. Comput. Decis. Sci. 3 (2) (2014) 321-326.

[33] S. Wan, L.-L. Lin, J. Dong, MAGDM based on triangular Atanassov's intuitionistic fuzzy information aggregation, Neural Comput. Appl., no. February, 2016.

[34] D.O. Aikhuele, S. Odofin, A generalized triangular intuitionistic fuzzy geometric averaging operator for decision-making in engineering and management, Information 8 (3) (2017) 1-17.

[35] A. Sachdeva, D. Kumar, Pradeep Kumar, Multi-factor failure mode critically analysis using TOPSIS, princessaliceadoptionhome.org 9(8) (2009) pp. 1-9. 
$\mathrm{ACI}$

$16,1 / 2$

194
[36] B. Vahdani, M. Salimi, M. Charkhchian, A new FMEA method by integrating fuzzy belief structure and TOPSIS to improve risk evaluation process, Int. J. Adv. Manuf. Technol. 77 (1-4) (2015) 357-368.

[37] H. Zhao, J.-X. You, H.-C. Liu, Failure mode and effect analysis using MULTIMOORA method with continuous weighted entropy under interval-valued intuitionistic fuzzy environment, Soft. Comput. (2016).

\section{Corresponding author}

Daniel O. Aikhuele can be contacted at: danbishop_22@yahoo.co.uk

For instructions on how to order reprints of this article, please visit our website: www.emeraldgrouppublishing.com/licensing/reprints.htm Or contact us for further details: permissions@emeraldinsight.com 